Artur Myśliwiec ${ }^{1}$, Przemysława Jarosz-Chobot ${ }^{2}$, Małgorzata Myśliwiec ${ }^{3}$, Krzysztof Strojek ${ }^{4}$, Paweł Piątkiewicz ${ }^{5}$, Mieczysław Walczak ${ }^{6}$, Władysław Grzeszczak Beata Koń ${ }^{8}$, Milena Kozioł ${ }^{8}$, Barbara Więckowska ${ }^{8}$

${ }^{1}$ Gdansk University of Physical Education and Sport, Neophilological Department of the Ateneum University in Gdansk, Poland ${ }^{2}$ Department of Children's Diabetology, School of Medicine in Katowice, Medical University of Silesia, Katowice, Poland

${ }^{3}$ Department of Pediatrics, Diabetology and Endocrinology, Medical University, Gdansk, Poland

${ }^{4}$ Department of Internal Diseases Diabetology and Cardiometabolic Diseases, School of Medicine with the Division of Dentistry (SMDZ) in Zabrze, Medical University of Silesia, Katowice, Poland

${ }^{5}$ Department of Internal Diseases, Diabetology and Endocrinology, Medical University, Warsaw, Poland

${ }^{6}$ Department of Pediatrics, Endocrinology, Diabetology, Metabolic Diseases and Cardiology of the Developmental Age, Pomeranian Medical University, Szczecin, Poland

${ }^{7}$ Department of Internal Medicine, Diabetology and Nephrology, School of Medicine with the Division of Dentistry in Zabrze, Medical University of Silesia, Katowice, Poland

${ }^{8}$ Department of Analysis and Strategy, Ministry of Health, Collegium of Economic Analysis, Warsaw School of Economics, Poland

\title{
Pediatric diabetes care: inpatient care in the Maps of Health Needs of Poland in 2014
}

\section{ABSTRACT}

Health care provision for patients with diabetes mellitus is a considerable challenge to health policy due to the increasing number of its new cases, both in adults and in children. In Poland, hospital care for children with diabetes mellitus is centralized and most services are provided by university and provincial hospitals. In spite of the above the structure of the services provided varies widely from province to province, both in terms of the number of hospitalizations per 100,000 children, net migration rate, length of hospital the stay, and percentage of hospitalizations for acute complications. It is necessary to improve the societal and medical awareness regarding the signs and symptoms of diabetes in order to reduce the number of acute complications, including those at the time of diagnosis. Furthermore, it is crucial to make every effort to provide equal access to specialist diabetes care, thus to make it consistent with the standards.

The high number and differences in the numbers, duration of hospitalizations of children with diabetes

Address for correspondence:

mgr Artur Myśliwiec

Zakład Fizjologii Sportu

Akademii Wychowania Fizycznego i Sportu

ul. Kazimierza Górskiego 1, 80-336 Gdańsk

e-mail: admysliwiec@wp.pl

Clinical Diabetology 2018, 7, 6, 259-271

DOI: $10.5603 /$ DK.2018.0028

Received: 18.05.2018

Accepted: 03.11.2018 require further monitoring at a coordinated system of pediatric care. (Clin Diabetol 2018; 7, 6: 259-271)

Key words: acute complications of diabetes, hospitalization, children, diabetes, pediatric diabetes care

\section{Introduction}

In 2006, the World Health Organization (WHO) placed diabetes mellitus among the four non-communicable diseases with the highest mortality [1]. The number of new cases of diabetes mellitus constantly increases, also in the case of children and adolescents, making diabetes one of the most common chronic diseases of the pediatric population [1, 2]. Diabetology in children and adolescents is a serious challenge to health policy in every country due to its social character and sustained growth rate of disease. At the same time, diabetes mellitus has become one of the most common chronic diseases of the developmental age. According to the International Diabetes Foundation (IDF), approximately 86 thousand new cases of type 1 diabetes mellitus are recorded in children each year worldwide, and the annual increase in incidence in the pediatric population is estimated at $3 \%$ [3].

All of the known types of diabetes mellitus according to the WHO classification are diagnosed in the pediatric population, with type 1 diabetes mellitus 
markedly prevailing in the Caucasian population. In the population of Poland, nearly $98 \%$ of diabetic children and adolescents suffer from type 1 diabetes mellitus, an autoimmune disease. Insulin, in the model of functional intensive insulin therapy with doses adjusted to the meals and everyday activities and accompanied by self-monitoring, is the only recommended life-saving treatment option in these cases [4, 5]. No primary preventive measures are currently available in type 1 diabetes mellitus. Secondary prevention, which aim is to minimize the development of diabetic complications, remains an essential element of patient care [4-6].

Diabetes care in children and adolescents poses a wide set of challenges to any country's healthcare system due to complex treatment regimen. In Poland and in some other countries, the system of pediatric diabetes care is centralized [7]. Each provincial administrative region has one or two (depending on the region, size and history) facilities that provide specialist inpatient and outpatient diabetes care services to children and adolescents up to 18 years of age. Also, in accordance with the relevant recommendations, each new case of type 1 diabetes mellitus requires hospitalization in order to implement a holistic full-range diabetes management [4]. Pediatric diabetes care is quite an exceptional type of care. From the onset of the child's diabetes is brittle, their care requires holistic solutions and understanding the need for achieving the best possible and durable treatment effects from the viewpoints of the patient, the patient's immediate surrounding and the society as a whole $[4,5,8]$. As a consequence, the magnitude of the problem needs to be estimated, including the direct and indirect costs of diabetes based on national registries and healthcare services [7-12].

While there is no formal national registry dedicated to patients with diabetes in Poland, various research studies and publications are available based on regional research registries which report information on the numbers of patients and on the costs of diabetes treatment [13-16].

These publications include the Maps of Health Needs published in 2016 by the Ministry of Health. Diabetes was among the 32 disease groups identified for which a separate map was created [6]. In accordance with the relevant Regulation of the Minister of Health [17], the map consisted of three elements: (I) demographic and epidemiological aspects, (II) an analysis of the state and utilization of the resources, and (III) forecasts. Part (II) of the publication is worth noting, as it presents the structure of healthcare services provided to patients with diabetes, both as part of inpatient treatment and outpatient specialist care. These documents were prepared as part of the project entitled: "Maps of Health Needs: A Systemic and Implementation Analyses Base" co-financed by the European Union from the European Social Fund as part of the Operational Program Knowledge Education Development. The project is ran by the Analyses and Strategies Department, Ministry of Health (project number: POWR.05.02.00-00-0149/15-01).

The maps of health needs are a tool that supports the decision process in healthcare and are used to develop regional healthcare policy and evaluate investment plans, and are employed by the public payer in the process of commissioning healthcare services. Developing the maps of health needs required collaboration that reached beyond the group of public health experts and statisticians/IT specialists and involved expert practitioners/diabetes specialists selected in a contest organized by the Ministry of Health. The interpretation of collated data and results was subject to difficult and stringent assessment by the entire working group and to wider consultations in the professional community [6].

The aim of the study was to analyze hospitalizations of children and adolescents due to diabetes mellitus in Poland in 2014.

\section{Material and methods}

For the purpose of this study, we used individual Polish National Health Fund (NFZ) data, i.e. database including patient ID (PESEL) and information on provided services. Data from 2014 were used, where the year refers to the date of the end of service provision. The services/provisions were defined as hospitalizations reported to the NFZ by health care providers within the $1 \mathrm{a}$ and $1 \mathrm{~b}$ catalogues, i.e. hospitalizations reported diagnosis related groups (DRGs, polish JGP) or distinct products [18].

The study analyzed the hospitalizations of children due to diabetes defined on the basis of the International Statistical Classification of Diseases and Related Health Problems ICD-10 [19] (Table 1, 2). We analyzed hospitalizations with the main diagnosis codes E10-E15 and E74.9. We also included codes E66 and E78, for which the coexisting diagnoses codes E10-E15 and E74.9 were reported. Hospitalizations with procedure 39.95 (haemodialysis) according to ICD-9-CM were excluded from the analysis.

The study presents a list of statistics at the national and provincial level in 2014. The analysis was conducted on the basis of the NFZ data on hospital treatment including 8.61 thousand hospitalizations for 6.90 thousand patients. The above analysis was completed by using the statistical program R. Additionally, in the demographic analysis, the studied population was di- 
Table 1. ICD-10 codes considers in article

\begin{tabular}{ll}
\hline ICD-10 & Disease \\
\hline E10 & Type 1 diabetes mellitus* \\
E11 & Type 2 diabetes mellitus* \\
E12 & Malnutrition-related diabetes mellitus* \\
E13 & Other specified diabetes mellitus* \\
E14 & Unspecified diabetes mellitus* \\
E15 & Nondiabetic hypoglycaemic coma \\
E74.9 & Disorder of carbohydrate metabolism, unspecified \\
E66 & Obesity \\
E66.0 & Obesity due to excess calories \\
E66.1 & Drug-induced obesity \\
E66.2 & Extreme obesity with alveolar hypoventilation \\
E66.8 & Other obesity \\
E66.9 & Obesity, unspecified \\
E78 & Disorders of lipoprotein metabolism and other \\
& lipidaemias \\
E78.0 & Pure hypercholesterolaemia \\
E78.1 & Pure hyperglyceridaemia \\
E78.2 & Mixed hyperlipidaemia \\
E78.3 & Hyperchylomicronaemia \\
E78.4 & Other hyperlipidaemia \\
E78.5 & Hyperlipidaemia, unspecified \\
E78.6 & Lipoprotein deficiency \\
E78.8 & Other disorders of lipoprotein metabolism \\
\hline
\end{tabular}

*Means all ICD-10 codes with subdivisions defined in Table 2

vided into 4 age group: $0-4,5-9,10-14,15-17$ years of age and the structure of hospitalization in relation to the place where the patient was provided and residing.

The analysis of pediatric hospitalizations due to diabetes also included acute diabetic complications.
Table 2. ICD-10 subdivisions for E10-E14

\begin{tabular}{l}
\hline Subvdvisions for E10-E14 \\
\hline .0 with coma \\
.1 ketoacidosis \\
.2 with renal complications \\
.3 with opthalmic complications \\
.4 with neurological complications \\
.5 with peripheral circulatory complications \\
.6 with other specified complications \\
.7 with multiple complications \\
.8 with unspecified complications
\end{tabular}

The following ICD-10 codes were considered as acute diabetic complications: diabetes mellitus with coma (ICD-10 codes E10.0, E11.0), diabetes mellitus with ketoacidosis (ICD-10 codes E10.1, E11.1) and diabetes mellitus with other specific complications (ICD-10 codes E10.6, E11.6).

New case of diabetes was defined as a patient up to 18 years of age, for whom no health care provisions due to diabetes were reported in 2009 (defined according to ICD-10 according to the codes described above) in the outpatient specialist care or inpatient care and who were hospitalized due to these diagnoses in 2014.

The publication presents a set of descriptive statistics at the national and provincial levels. The analysis was carried out using $R$ (a software for statistics).

\section{Results}

In Poland, in the year 2014, a total of 6.90 thousand children were hospitalized due to diabetes. The age group between 10 to 14 years old accounted for the largest percentage (41\%) of patients aged below 18 years (Figure 1). There were no sex differences in

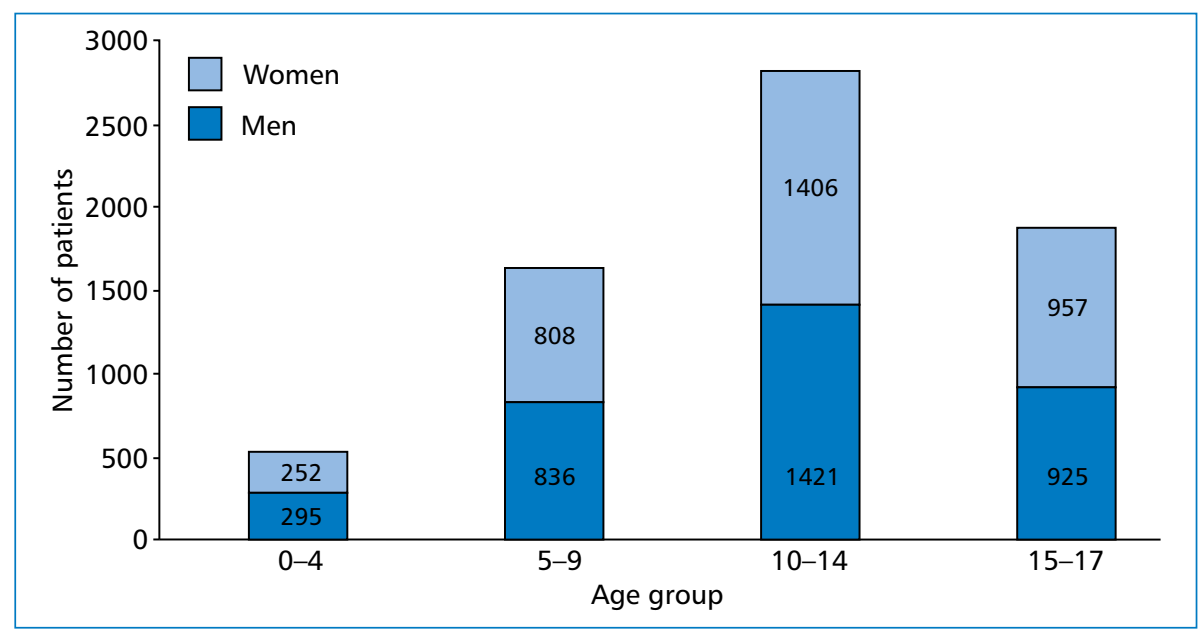

Figure 1. Age structure of children hospitalized for diabetes 


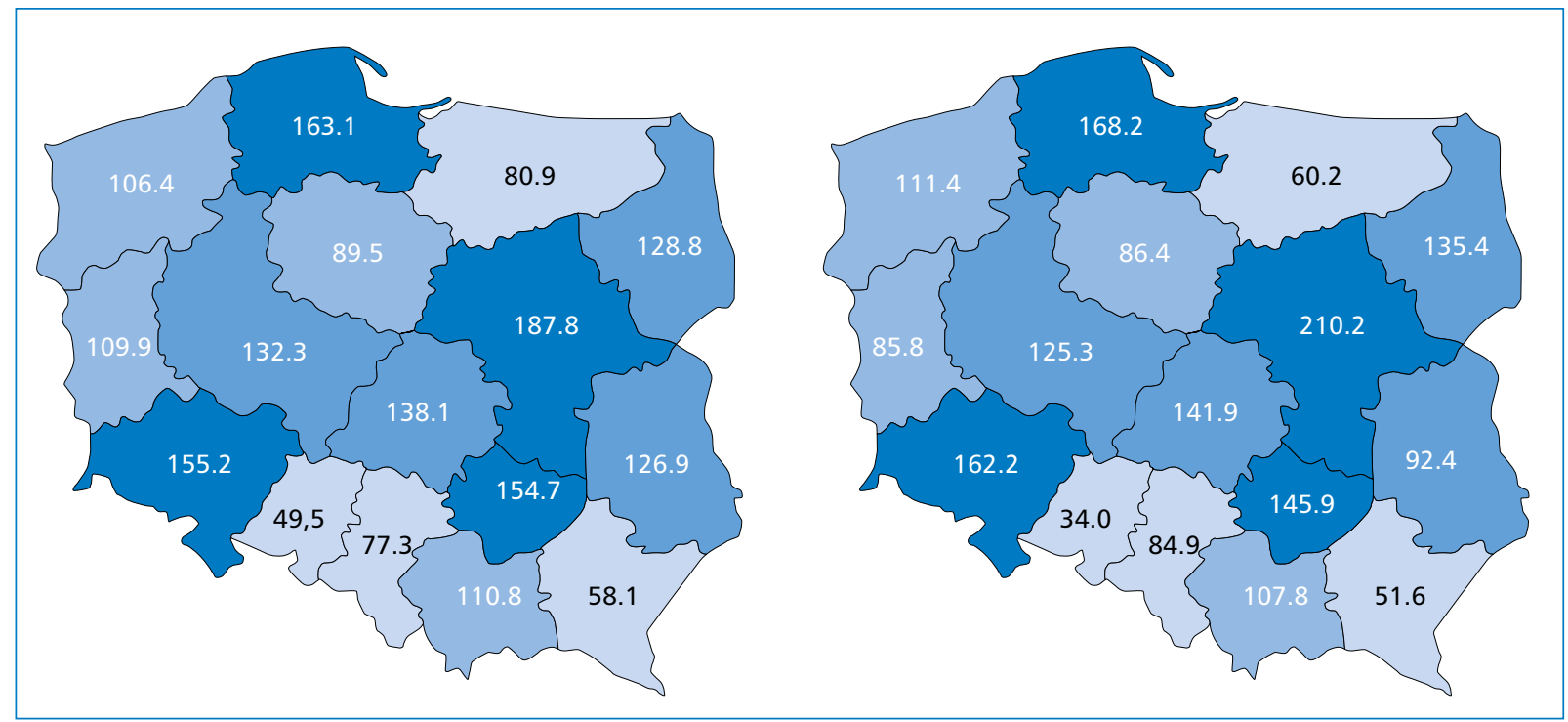

Figure 2. The number of hospitalizations of patients according to the place of residence (left map) and the number of hospitalizations according to the place of service provision (right map) per 100,000 children

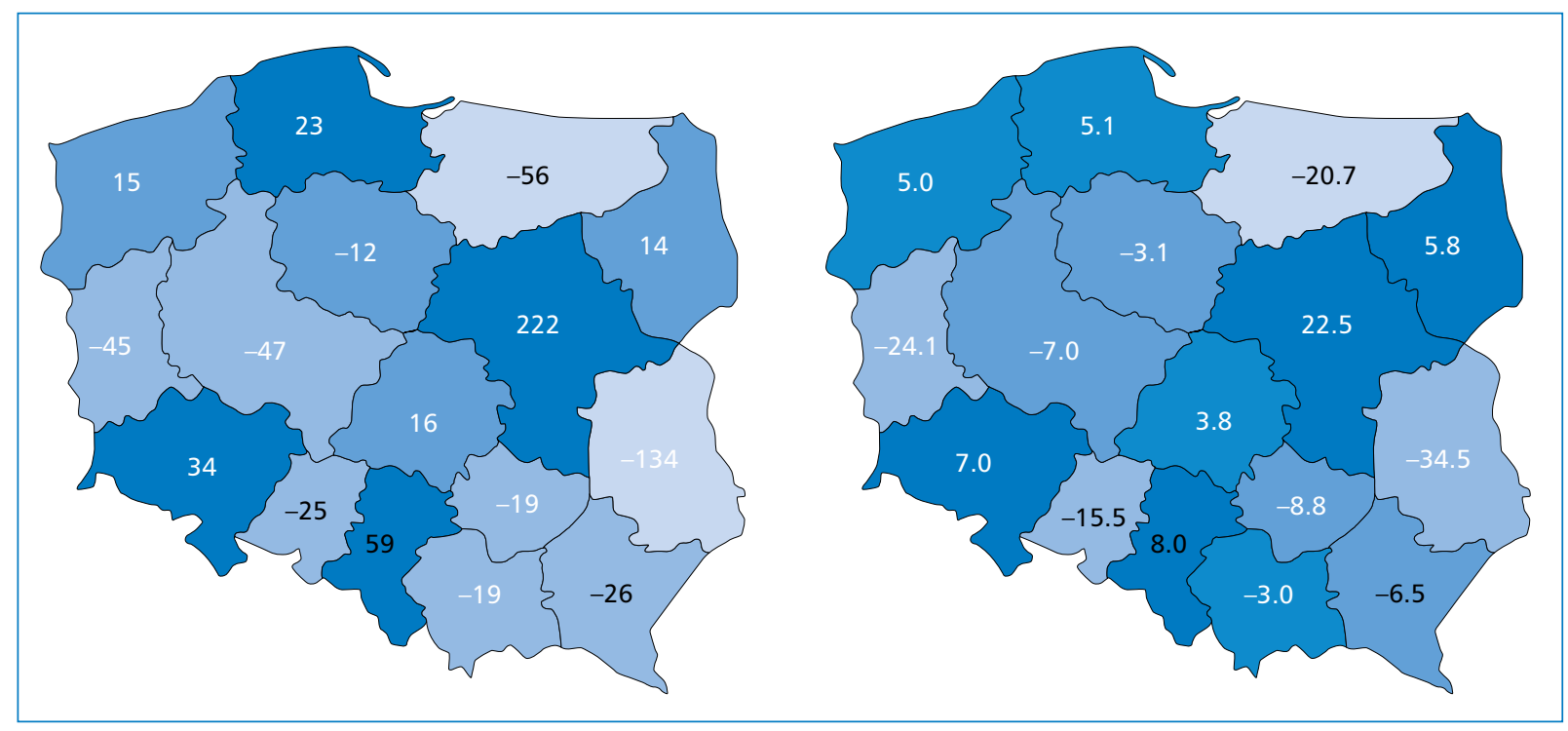

Figure 3. Net migration rate of children with diabetes (left map) and net migration rate of children with diabetes per 100,000 children (right map); hospital services

hospitalization rates (with both females and males accounting for $50 \%$ of all hospitalizations).

A total of 8.61 thousand hospitalizations due to diabetes were reported in Poland among children. This means that in Poland, on average, each child with diabetes was hospitalized 1.25 times. The number of hospitalizations per 100,000 children and adolescents in Poland was 125.

When expressed relative to the number of inhabitants in each province, children who were hospitalized the most frequently were inhabitants of the Mazovia, Pomerania, Lower Silesia and Świętokrzyskie Provinces (Figure 2). Children from the Opole and Podkarpackie Provinces were hospitalized the least frequently. When expressed relative to the number of all hospitalizations in a given province, similarly to the previous case, children from the Mazovia, Pomerania, Lower Silesia and Świętokrzyskie (Holy Cross) Provinces were hospitalized the most frequently, while those from the Opole and Podkarpackie Provinces were hospitalized the least 
frequently. The significant differences between the provinces are worth noting: almost a 4-fold difference between the Mazovia and Opole Provinces in the number of patients hospitalized according to the place of residence per 100,000 children, and over a 6 -fold difference between these provinces in the number of hospitalizations according to the place of service provision. The differences in the number of services according to the place of service provision and to the place of residence per 100,000 children suggest migration of children beyond their respective provinces of residence.

The highest net migration rate was identified for the Mazovia, Silesia, Pomerania and Lower Silesia Provinces (Figure 3). When expressed per 100,000 children inhabiting a given province, the lowest net migration rates were reported for the Lublin (-34.5) and Lubusz $(-24.5)$ Provinces. The highest net migration rate per 100,000 children was identified for the Mazovia and Silesia Provinces.

In absolute terms, the highest numbers of hospitalizations of children due to diabetes were reported in the Mazovia, Pomerania, Lower Silesia, Greater Poland and Lesser Poland Provinces (Table 3). The wide distribution of the proportions of one-day hospitalizations are worth noting, particularly in the Lower Silesia and Lesser Poland Provinces (nearly $60 \%$ and nearly $45 \%$ of all hospitalizations, respectively). As already indicated and discussed with respect to patient migration, the proportions of hospitalizations of patients from outside the province are widely distributed, with more than $10 \%$ of hospitalizations from outside the province being reported in the Mazovia, Silesia and West Pomerania Provinces.

The average length of stay (ALOS) for a child with diabetes in Poland is 4.6 days, with the longest ALOS of nearly 10 days being reported for the Podkarpackie Province, and the shortest, of about 3 days, for the Lesser Poland and Lower Silesia Provinces (Table 4). Of note is also the median length of stay (MLOS) of 1 day for the Lower Silesia Province. In terms of patient age, children aged 4 years are hospitalized the longest.

On a national level, the proportion of hospitalizations due to acute diabetic complications was $12.6 \%$, with the highest values reported for the Opole (36.4\%), Greater Poland (33.0\%) and Warmia-Masuria (26.4\%) Provinces. These provinces were also characterized by high hospitalization rates for acute complications among new patients, i.e. above $40 \%$ (Table 5 ). It is worth noting that the Greater Poland Province, with a considerable proportion of one-day hospitalizations (24\%) was reported additionally.

The hospitalizations of children due to diabetes were most frequent reported as with DRG code P24 (diabetes mellitus) - $88.2 \%$ of all hospitalizations [18] (Table 6). Another code, K28 (congenital metabolic disorders), was reported for $10.60 \%$ of all hospitalizations. For both codes, there is a wide variation between the provinces. Two provinces are particularly noteworthy: the Pomorskie Province, where hospitalizations were most commonly reported as DRG K28 (41.2\%), and the Warmia-Masuria Province, where hospitalizations due to diabetes with the DRG code K27B were relatively frequently reported.

In children, hospital diabetes care was strongly centralized, with $80 \%$ of the services being reported by 12 hospitals (Table 7). Except for the Mazovia Province, such services were provided by one hospital in each of the provinces, a university or a provincial hospital.

\section{Discussion}

Our study, concerning diabetes mellitus in the pediatric population was based on the Maps of Health Needs (2014). This publication is a summary and extension of the content presented in the Maps of Health Needs with regard to diabetes in the developmental age population.

We strongly emphasize that we are fully aware of the multiple difficulties, ambiguities and coding errors associated with the reporting of services by healthcare facilities to the National Health Fund in Poland. In addition, due to the great differences in the regional policy of NHF branches, for instance, the absence or availability of contracts for 1-day hospitalization, or in the limits of hospitalizations, in the number of available personal insulin pumps, et cetera. Nevertheless, this is the first ever, unique publication on this topic, authored by a diverse group of experts in diabetes and statistics, offering an important point of reference for future research papers in Poland.

The admittedly society-wide nature of this serious chronic disease, which affects young patients at the beginning of their lives and during the period of stormy development, requires a comprehensive context and multi-layered involvement both on the service provider's and service recipient's part, and at the level of the entire health policy. As a consequence, childhood diabetes has become a priority of health and social policies both in Poland and worldwide [2, 20-23].

Polish and global epidemiological forecasts unequivocally prove and predict a constant increase in the incidence of diabetes in the pediatric population, in post-communist countries, and an increase in the number of hospitalizations of patients with diabetes [24-28].

Poland can serve as an example, with its annual increase rate estimated at 9\%, 3-fold higher than the 


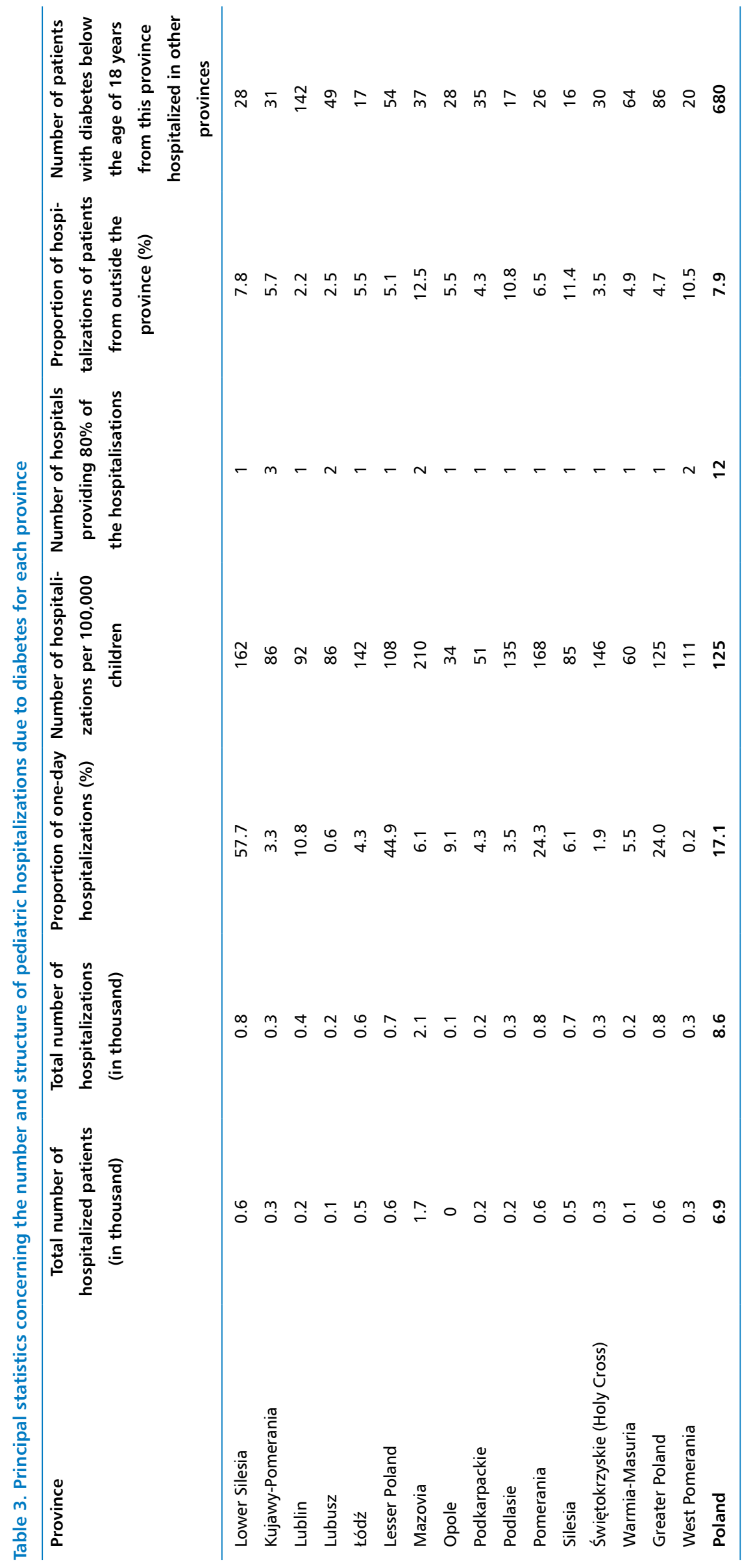


Table 4. Statistics on the length of pediatric hospitalization for diabetes for each province

\begin{tabular}{|c|c|c|c|c|c|c|}
\hline \multirow[t]{2}{*}{ Province } & \multirow{2}{*}{$\begin{array}{c}\text { MLOS (median } \\
\text { length of hospital } \\
\text { stay in days) }\end{array}$} & \multicolumn{5}{|c|}{$\begin{array}{c}\text { ALOS (average length of hospital stay in days) for the following } \\
\text { age groups of patients }\end{array}$} \\
\hline & & $0-4$ years & 5-9 years & 10-14 years & 15-17 years & Total \\
\hline Lower Silesia & 1 & 4.0 & 3.3 & 3.1 & 3.3 & 3.3 \\
\hline Kujawy-Pomerania & 4 & 8.2 & 5.7 & 5.9 & 4.8 & 5.9 \\
\hline Lublin & 5 & 7.3 & 6.4 & 7.4 & 6.1 & 6.9 \\
\hline Lubusz & 4 & 6.1 & 5.3 & 5.7 & 5.5 & 5.5 \\
\hline Łódź & 4 & 6.7 & 5.1 & 4.8 & 4.6 & 4.9 \\
\hline Lesser Poland & 2 & 5.7 & 3.4 & 3.0 & 2.8 & 3.2 \\
\hline Mazovia & 3 & 6.3 & 4.4 & 4.2 & 4.0 & 4.3 \\
\hline Opole & 6 & 5.0 & 5.6 & 5.3 & 3.4 & 5.1 \\
\hline Podkarpackie & 10 & 8.6 & 11.4 & 9.6 & 8.9 & 9.6 \\
\hline Podlasie & 4 & 7.7 & 5.6 & 5.4 & 4.5 & 5.5 \\
\hline Pomerania & 2 & 6.0 & 4.0 & 3.2 & 2.7 & 3.5 \\
\hline Silesia & 4 & 5.4 & 4.7 & 4.0 & 4.3 & 4.4 \\
\hline Świętokrzyskie (Holy Cross) & 3 & 8.8 & 5.7 & 5.1 & 4.4 & 5.3 \\
\hline Warmia-Masuria & 5 & 7.6 & 6.7 & 6.6 & 5.6 & 6.4 \\
\hline Greater Poland & 2 & 5.3 & 3.8 & 4.1 & 3.8 & 4 \\
\hline West Pomerania & 4 & 8.4 & 5.7 & 4.8 & 5.2 & 5.6 \\
\hline Poland & 3 & 6.3 & 4.7 & 4.4 & 4.1 & 4.6 \\
\hline
\end{tabular}

European average $[25,26]$. This is no surprise, given that diabetes mellitus is a chronic disease of a societal scale. Moreover, according to multiple reports from Poland and abroad, the highest trend in the increased incidence of diabetes in the pediatric population is observed in the age group 0 to 9 years [29]. The systematic review published in 2007 documents the common fact of both: a high number - at least three times higher - as well as an extended time of children hospitalization - at least twice - with diabetes compared to the children without diabetes [28].

According to the Sayers et al. in the United Kingdom, the high number of hospitalizations of children with diabetes $(480 \%$ compared to the population of children without diabetes) has remained for more than a decade. Authors of this widely quoted article from BMJ (2015) indicate: annual increase in sickness (3-4\%) and socioeconomic status and care in a smaller diabetic center as one of the chief reasons for this trend [30].

The current, similar population data was presented by a group of German researchers. According to the German Information System for health care diabetes ( $n=12030242)$, it has been documented that the number of hospitalizations for children with diabetes is $4-5$ times higher, especially in the group of young children and adolescents [31].
At the same time, it should be noted that the diabetology education model in these countries is different. Diabetes education is separated in outpatient care. The educator is mobile, accompanying the child and family (often with close cooperation of social workers) both at home and at school (fires days at home after completing hospitalization of a child with newely diagnosed diabetes).

Poland, with its centralized pediatric diabetes care, is illustrated by the number of hospitalizations under healthcare services related to diabetes provided mainly in provincial and university facilities (Table 3 ). Regionalization of care has long been believed to be the best systemic solution for both Poland and the rest of the world; in terms of the quality and the economics of diabetes care. The 2017 International Diabetes Society for Pediatric and Adolescent Diabetes (ISPAD) provided new evidence to support that large pediatric diabetes centers achieve significantly superior treatment effects [32, 33]. Larger diabetes care centers allow to provide continuous, holistic, multidisciplinary care using new technologies to severely and chronically sick child and the child's family. On the other hand, while the accessibility to the services is similar, there are marked differences in diabetes care [23, 34]. To eliminate the differences, among the proposed solu- 


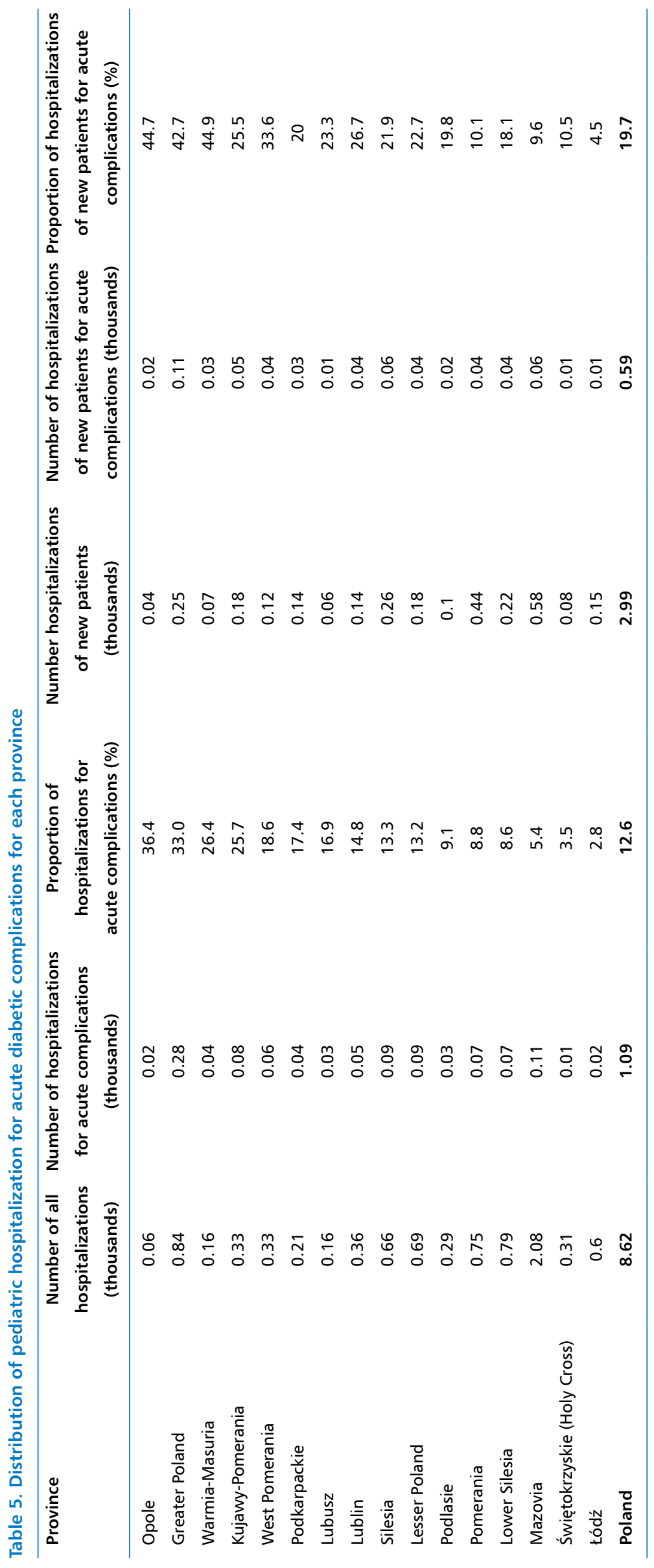


Table 6. Pediatric hospitalizations for diabetes in individual provinces according to DRG (\%)

\begin{tabular}{|c|c|c|c|c|c|}
\hline Province & $\begin{array}{l}\text { P24 } \\
\text { Diabetes } \\
\text { mellitus }\end{array}$ & $\begin{array}{c}\text { K28 } \\
\text { Congenital metabolic } \\
\text { disorders }\end{array}$ & $\begin{array}{c}\text { K27B } \\
\text { Eating disorders } \\
<18 \text { years of age }\end{array}$ & Other & $\begin{array}{c}\text { Number of hospitalizations } \\
\text { DRG (thousands) }\end{array}$ \\
\hline Lower Silesia & $93.3 \%$ & $6.4 \%$ & $0.0 \%$ & $0.3 \%$ & 0.78 \\
\hline Kujawy-Pomerania & $82.4 \%$ & $17.0 \%$ & $0.6 \%$ & $0.0 \%$ & 0.33 \\
\hline Lublin & $98.6 \%$ & $1.4 \%$ & $0.0 \%$ & $0.0 \%$ & 0.35 \\
\hline Lubusz & $98.7 \%$ & $1.3 \%$ & $0.0 \%$ & $0.0 \%$ & 0.16 \\
\hline Łódź & $99.3 \%$ & $0.0 \%$ & $0.2 \%$ & $0.5 \%$ & 0.60 \\
\hline Lesser Poland & $96.8 \%$ & $2.6 \%$ & $0.3 \%$ & $0.3 \%$ & 0.69 \\
\hline Mazovia & $80.3 \%$ & $17.4 \%$ & $0.4 \%$ & $1.9 \%$ & 2.07 \\
\hline Opole & $98.2 \%$ & $1.8 \%$ & $0.0 \%$ & $0.0 \%$ & 0.06 \\
\hline Podkarpackie & $97.1 \%$ & $1.5 \%$ & $1.0 \%$ & $0.5 \%$ & 0.21 \\
\hline Podlasie & $93.2 \%$ & $4.3 \%$ & $1.1 \%$ & $1.4 \%$ & 0.28 \\
\hline Pomerania & $58.2 \%$ & $41.2 \%$ & $0.3 \%$ & $0.4 \%$ & 0.75 \\
\hline Silesia & $94.1 \%$ & $5.1 \%$ & $0.6 \%$ & $0.2 \%$ & 0.63 \\
\hline Świętokrzyskie & $95.5 \%$ & $3.8 \%$ & $0.0 \%$ & $0.6 \%$ & 0.31 \\
\hline Warmia-Masuria & $89.3 \%$ & $2.5 \%$ & $6.9 \%$ & $1.3 \%$ & 0.16 \\
\hline Greater Poland & $96.7 \%$ & $2.6 \%$ & $0.7 \%$ & $0.0 \%$ & 0.82 \\
\hline West Pomerania & $94.3 \%$ & $5.1 \%$ & $0.3 \%$ & $0.3 \%$ & 0.33 \\
\hline Poland & $88.2 \%$ & $10.6 \%$ & $0.5 \%$ & $0.7 \%$ & 8.51 \\
\hline
\end{tabular}

tions, is the implementation of facility benchmarks in terms of treatment effects, and adaptation to national and international guidelines for diabetes care provided to children.

In Poland, a high number of hospitalizations of children and adolescents for diabetes at specialized facilities varies from province to province. In individual provinces, a high number of one-day hospitalizations (financial policy of regional branches of the National Health Fund) impact both: the number of general hospitalizations and the high differences between voivodships. Moreover, the number of hospitalizations often overlaps with the net migration rate. It is likely that those service-providing facilities where the proportion hospitalizations of patients from outside the province is high, and the number of patients from this particular province hospitalized in other provinces is low, are resilient facilities with a vast potential for providing treatment, education and psychological support. They are usually large diabetic centers, thus the facilities that provide holistic diabetes care and high quality, with a wider access and use of new technologies for the monitoring and treatment of the disease [30].

Rapid technological progress and social media are both important and common elements of pediatric diabetes care $[35,36]$. Young parents and caregivers actively browse Polish and international websites in search of the best possible and most effective treatment solutions for their children. As a consequence, they share their experiences on various forums, recommend diabetes facilities and support one another in their everyday lives with diabetes. Based on the above, it may be concluded that in the Mazovia, Silesia, Lower Silesia, Podlasie, Pomerania, Łódź and West Pomerania Provinces, large-scale pediatric diabetes care and the scope of services provided "attract" children, adolescents and their caregivers from smaller provinces. A particularly high outflow of patients is observed for the Lublin, Lubusz, Warmia-Masuria, Opole, Świętokrzyskie (Holy Cross), Greater Poland and Podkarpackie Provinces. This finding should be interpreted carefully and with caution, and on two levels; in terms of regional health policy (e.g. extent of commissioning by the National Health Fund, number of diabetes beds) and the quality of medical care (e.g. number of diabetes specialists, nurses, educators, dietitians, psychologists, compliance with the current standards of diabetes care, treatment efficacy and the number of available insulin pumps) $[4,5,37]$.

The duration of the diabetic child's stay (defined as the average length of hospitalization) at a hospital ward varies from province to province, averaging 4.6 days for the whole of Poland (Table 4). As mentioned above another difficulty in this assessment is the diversity in hospitalization contracts between individual diabetes facilities and the National Health Fund, both 


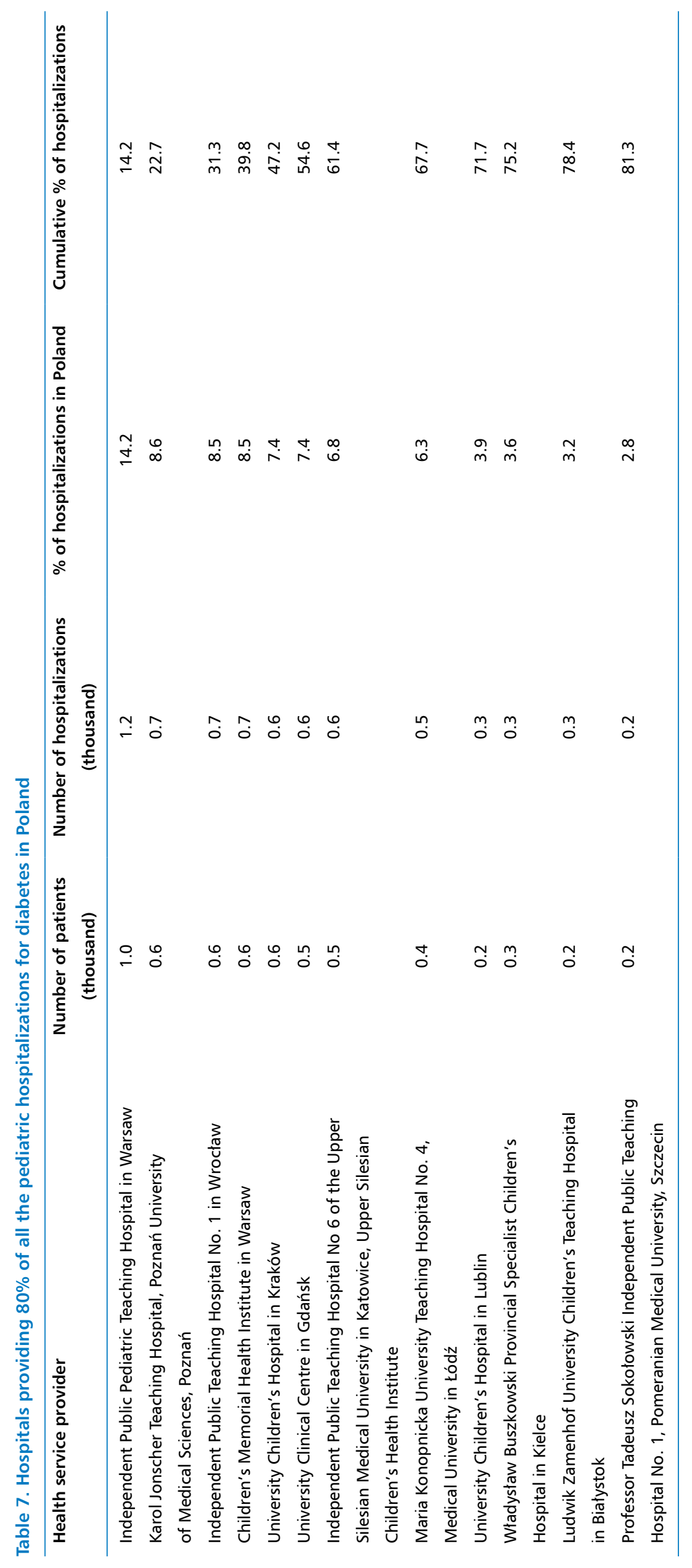


in terms of score value and the presence/absence of the so-called one-day hospitalization. However, the longest average lengths of stay (ALOS) values are quite striking, with the highest ALOS values of 9.6 days in the Podkarpackie Province and 6.9 days in the Lublin Province, where the proportion of one-day hospitalizations is quite considerable ( $58 \%$ for the Lower Silesia, $45 \%$ for the Lesser Poland, 24\% for the Greater Poland and $24 \%$ for the Pomerania Provinces). It may be hypothesized that such extreme differences result from the fact that diabetes care is organized in specialist inpatient departments providing hospital services in diabetes care (apart from one-day hospitalization) as well as, for instance, social and economic (poverty) or communication factors (difficult remote access), area and urbanization of the province. In all the facilities, the longest duration of hospitalization was observed among the youngest children, which is understandable and is directly associated with the low stability of a young child's body.

Acute diabetic complications are a manifestation of many elements, with the following being the most important: awareness in the society, education of healthcare professionals on the signs and symptoms of diabetes and on the need for rapid medical intervention, extent of diabetes care and social care (e.g. frequent occurrence of emotional problems and depression in adolescents). The process requires ongoing and consistent activity in all the above, wide fields. The proportion of acute admission to hospital in Poland is $12.6 \%$. In four provinces, the Opole, Greater Poland, Warmia-Masuria and Kujawy-Pomerania Provinces, this proportion is at least twice as high. Again, while the reporting is correct in these provinces, it should, however, be assumed that this finding poses a challenge to these regions, their specialist pediatrics diabetes care and the improvement of the overall awareness in the society and among the primary care physicians regarding the initial manifestations of diabetes mellitus [38, 39].

With regard to the acute complications occurring in first-ever patients with diabetes, this value averaged $20 \%$, similarly to the total number, with a wide variation of results (Table 5). While the objections about the reporting remain the same, the high value, exceeding $40 \%$, requires interventions of the appropriate structures of healthcare. It is assumed that $30 \%$ rate of acute complications, namely diabetic ketoacidosis, in children recently diagnosed with type 1 diabetes mellitus is considered high [40].

Results of the analysis of the reporting of all the pediatric hospitalizations for diabetes to the National Health Fund according to DRGs have shown that the group P24 directly dedicated to diabetes was utilized in nearly $90 \%$. Only in several provinces, the code $\mathrm{K} 28$, which refers to congenital metabolic disorders and often includes extended diagnostic evaluation in pediatric diabetes care, was additionally used in reconciliation. For example, extending the diagnostic evaluation to include genetic testing for monogenic forms of diabetes or hypoglycaemia, often requires indicating the code $\mathrm{K} 28$ to have the costs paid for. This case is difficult to interpret due to the considerable difference in score pricing of the hospitalization under both codes. It may, however, be alleged that hospitals that provide services qualifying under this code offer a wider range of medical services, especially given the fact that in many cases, this findings remains consistent with the net migration rate. However, in the analysis above, in addition to considering incorrect coding, the value of the diabetes score contract between a given facility and the National Health Fund should be taken into account.

As already mentioned, several limitations of this study exist. The first limitation is the absence of a supplementary analysis based on the extended database with information on, for example, typical medicines (insulin, glucagon), test strips assigned to individual ICD-10 diagnoses. Unfortunately, the authors had no access to the medicines database at the time of developing the maps of health needs in 2016. The second limitation refers to the coding of hospitalization services, which are often routine, given the same pricing by the National Health Fund. Another limitation refers to the differences in the commissioning of hospitalization services by individual facilities in individual provinces (e.g. presence or absence of contracts commissioning one-day hospitalizations, access to new technologies). In addition, the authors did not analyze medical procedures due to the absence of appropriate reporting (procedures are not scored or priced voluntarily). Nevertheless, the present publication is the first so extensive scientific analysis of this topic for Poland.

\section{Summary}

In Poland, specialized diabetes care for children and adolescents is regionalized. Nevertheless, there are significant differences in the number of hospitalizations per 100,000 . children and in the average length of stay of patients in the hospital.

High number and differences in the numbers, duration of hospitalization of children with diabetes require further monitoring at a coordinated system of pediatric care. It is crucial to create coordinated care system for children - by identifying reference centers and supporting cooperation with outpatient specialist care facilities. In addition, significant patient 
migrations point to the need to align pediatric diabetes care standards.

It is necessary to improve the societal and medical awareness regarding the signs and symptoms of diabetes to reduce the number of acute complications, including those at the time of diagnosis.

An absolute requirement is to increase the quality of reporting in terms of both coding and procedures performed in patients, so that, in the future, reference centers that can be added to bear the additional costs of diagnosis and care of a difficult patient. This would cause the introduction of new JGP groups that better reflect the specificity of treatment. It would be very important to regularly (at least once a year) monitor the path of patients, including medicines and glucose test strips, based on the latest data. This could be done by appropriate cooperation of National Health Fund bases or through the appropriate clinical registry. Due to the between provinces differences in children's hospitalizations related to diabetes, we should make every effort to provide equal access to specialists diabetes care in order to provide specialist care in accordance with the standards.

In addition, constant cooperation with provincial and national consultants in the area of problems related to pediatric diabetology in Poland is necessary.

\section{Conclusions}

Due to the differences between provinces in the number of children hospitalizations due to diabetes, one it is crucial to strive to equalize access to specialist diabetes care in order to ensure its compliance with its standards.

\section{Conflict of interests statements}

The authors do not declare any conflict of interests.

\section{Acknowledgements}

The authors wish to thank all those involved in the process of developing the maps of health needs, especially national and provincial consultants, who contributed valuable comments on the issues addressed in the map. We hope that publications like this will be prepared regularly, as the trend analysis may be an important policy-informing element to continuous improvement of the quality of pediatric diabetes care in Poland.

\section{REFERENCES}

1. World Health Organization (WHO), Global Action Plan for the Prevention and Control of Noncommunicable diseases 2013-2020, Geneva, 2013. http://apps.who.int/iris/bitstre am/10665/94384/1/9789241506236_eng.pdf (02.06.2017).
2. Mathers $C D$, Loncar $D$. Projections of global mortality and burden of disease from 2002 to 2030. PLoS Med. 2006; 3(11): e442, doi: 10.1371/journal.pmed.0030442, indexed in Pubmed: 17132052.

3. International Diabetes Federation, IDF Diabetes Atlas. Seventh Edition, 2015. http://www.diabetesatlas.org (01.06.2017).

4. Polskie Towarzystwo Diabetologiczne. Zalecenia kliniczne dotyczące postepowania w chorych na cukrzycę 2018. Stanowisko Polskiego Towarzystwa Diabetologicznego. Diabetologia Praktyczna. 2018; 3(supl. A): 47-53.

5. Aktualne (2014) wytyczne International Society for Pediatric and Adolescent Diabetes (ISPAD). Medycyna Praktyczna Pediatria, Wydanie Specjalne. 2015; 5.

6. Ministerstwo Zdrowia. Mapy potrzeb zdrowotnych w zakresie cukrzycy. http://www.mapypotrzebzdrowotnych.mz.gov.pl/mapydla-30-grup-chorob/ (31.05.2017).

7. Coppell KJ, Anderson K, Williams SM, et al. The quality of diabetes care: a comparison between patients enrolled and not enrolled on a regional diabetes register. Prim Care Diabetes. 2011; 5(2): 131-137, doi: 10.1016/j.pcd.2010.10.005, indexed in Pubmed: 21126933.

8. Katsarou A, Gudbjörnsdottir S, Rawshani A, et al. Type 1 diabetes mellitus. Nat Rev Dis Primers. 2017; 3: 17016, doi: 10.1038/ nrdp.2017.16, indexed in Pubmed: 28358037.

9. Coppell K, Manning P. Otago Diabetes Team. Establishing a regional diabetes register and a description of the registered population after one year. N Z Med J. 2002; 115(1160), indexed in Pubmed: 12362203.

10. O'Mullane M, McHugh S, Bradley C. Informing the development of a national diabetes register in Ireland: a literature review of the impact of patient registration on diabetes care. Journal of Innovation in Health Informatics. 2010; 18(3): 157-168, doi: 10.14236/jhi.v18i3.768.

11. Stone MA. Quality is essential in diabetes disease registers. Inform Prim Care. 2010; 18(3): 169-170, indexed in Pubmed: 21396239.

12. Malone C, Kennedy GD. Pediatric diabetes registries: when baby steps are not enough. J Diabetes Sci Technol. 2011; 5(3): 571-578, doi: 10.1177/193229681100500311, indexed in Pubmed: 21722572.

13. Instytut Praw Pacjenta i Edukacji Zdrowotnej, Koalicja na Rzecz Walki z Cukrzycą, et al. Cukrzyca 2025. Strategia Prewencji i Leczenia Cukrzycy w Polsce. 2015.

14. Cukrzyca. Ukryta pandemia. Sytuacja w Polsce. Edycja 2014. http://www.pfed.org.pl/aktualno347ci/cukrzyca-ukryta-pandemia-2014 (07.07.2017).

15. Kawalec P, Pilc A. Koszty pośrednie cukrzycy w Polsce. Diabetologia Praktyczna. 2006; 7(4): 211-215.

16. Kawalec P, Kielar M, Pilic A. Koszty leczenia cukrzycy typu 1 i 2 w Polsce. Diabetologia Praktyczna. 2006; 7(5): 287-294.

17. Rozporządzenie Ministra Zdrowia z dnia 26 marca 2015 r. w sprawie zakresu treści map potrzeb zdrowotnych. (Dz.U. 2015 poz. 458).

18. Zarządzenie NR 89/2013/DSOZ Prezesa Narodowego Funduszu Zdrowia z załącznikami, katalog $1 \mathrm{a}, 1 \mathrm{~b}$

19. Centrum Systemów Informacyjnych Ochrony Zdrowia. Międzynarodowa Statystyczna Klasyfikacja Chorób i Problemów Zdrowotnych. Rewizja dziesiąta. 2008; I.

20. Sørensen M, Arneberg F, Line TM, et al. Cost of diabetes in Norway 2011. Diabetes Res Clin Pract. 2016; 122: 124-132, doi: 10.1016/j. diabres.2016.10.012, indexed in Pubmed: 27837695.

21. American Diabetes Association. Economic costs of diabetes in the U.S. in 2012. Diabetes Care. 2013; 36(4): 1033-1046, doi: 10.2337/dc12-2625, indexed in Pubmed: 23468086.

22. Schwandt A, Hermann JM, Rosenbauer J, et al. DPV Initiative. Longitudinal Trajectories of Metabolic Control From Childhood to Young Adulthood in Type 1 Diabetes From a Large German/ /Austrian Registry: A Group-Based Modeling Approach. Diabetes Care. 2017; 40(3): 309-316, doi: 10.2337/dc16-1625, indexed in Pubmed: 28007778. 
23. Witsch $\mathrm{M}$, Kosteria I, Kordonouri $\mathrm{O}$, et al. Possibilities and challenges of a large international benchmarking in pediatric diabetology-The SWEET experience. Pediatr Diabetes. 2016; 17(Suppl 23): 7-15, doi: 10.1111/pedi.12432, indexed in Pubmed: 27982492.

24. Leśniowska J, Schubert A, Wojna M, et al. Costs of diabetes and its complications in Poland. Eur J Health Econ. 2014; 15(6): 653-660, doi: 10.1007/s10198-013-0513-0, indexed in Pubmed: 23820625.

25. Chobot A, Polanska J, Brandt A, et al. Updated 24-year trend of Type 1 diabetes incidence in children in Poland reveals a sinusoidal pattern and sustained increase. Diabet Med. 2017; 34(9): 1252-1258, doi: 10.1111/dme.13345, indexed in Pubmed: 28257151.

26. Chobot A, Polanska J, Deja G, et al. Incidence of type 1 diabetes among Polish children ages $0-14$ years from 1989-2012. Acta Diabetol. 2015; 52(3): 483-488, doi: 10.1007/s00592-014-0682-z, indexed in Pubmed: 25381194.

27. Patterson CC, Gyürüs E, Rosenbauer J, et al. Seasonal variation in month of diagnosis in children with type 1 diabetes registered in 23 European centers during 1989-2008: little short-term influence of sunshine hours or average temperature. Pediatr Diabetes. 2015; 16(8): 573-580, doi: 10.1111/pedi.12227, indexed in Pubmed: 25316271.

28. Angus VC, Waugh N. Hospital admission patterns subsequent to diagnosis of type 1 diabetes in children: a systematic review. BMC Health Serv Res. 2007; 7: 199, doi: 10.1186/1472-6963-7-199, indexed in Pubmed: 18053255.

29. Torio C, Elixhauser A, Andrews R. Trends in potentially preventable hospital admissions among adults and children 2005-2010. Healthcare Cost and Utilization Project (HCUP) Statistical Briefs [Internet]. Rockville (MD): Agency for Healthcare Research and Quality (US). 2006-2013 Mar.

30. Sayers A, Thayer D, Harvey JN, et al. Evidence for a persistent, major excess in all cause admissions to hospital in children with type-1 diabetes: results from a large Welsh national matched community cohort study. BMJ Open. 2015; 5(4): e005644, doi: 10.1136/bmjopen-2014-005644, indexed in Pubmed: 25869680.

31. Bohn B, Schwandt A, Ihle $P$, et al. Hospital admission in children and adolescents with or without type 1 diabetes from Germany: An analysis of statutory health insurance data on 12 million subjects. Pediatr Diabetes. 2017; 19(4): 721-726, doi: 10.1111/ pedi.12621, indexed in Pubmed: 29226514.
32. Fullerton $B$, Jeitler $K$, Seitz $M$, et al. Intensive glucose control versus conventional glucose control for type 1 diabetes mellitus. Cochrane Database Syst Rev. 2014(2), doi: 10.1002/14651858. CD009122.pub2, indexed in Pubmed: 24526393.

33. Shalitin S, Peter Chase H. Diabetes technology and treatments in the paediatric age group. Int J Clin Pract Suppl. 2011(170): 76-82, doi: 10.1111/j.1742-1241.2010.02582.x, indexed in Pubmed: 21323816.

34. Swift PG, Skinner TC, de Beaufort CE, et al. Target setting in intensive insulin management is associated with metabolic control: the Hvidoere childhood diabetes study group centre differences study 2005. Pediatr Diabetes. 2010; 11(4): 271-278, doi: 10.1111/j.13995448.2009.00596.x, indexed in Pubmed: 19895567.

35. Giménez-Pérez G, Recasens A, Simó $O$, et al. Use of communication technologies by people with type 1 diabetes in the social networking era. A chance for improvement. Prim Care Diabetes. 2016; 10(2): 121-128, doi: 10.1016/j.pcd.2015.09.002, indexed in Pubmed: 26428527.

36. Ng SM. Improving patient outcomes with technology and social media in paediatric diabetes. BMJ Qual Improv Rep. 2015; 4(1), doi: 10.1136/bmjquality.u209396.w3846, indexed in Pubmed: 26734405.

37. Hanberger L, Ludvigsson J, Nordfeldt S. Health-related quality of life in intensively treated young patients with type 1 diabetes. Pediatr Diabetes. 2009; 10(6): 374-381, doi: 10.1111/j.13995448.2008.00496.x, indexed in Pubmed: 19207230.

38. Ilkowitz JT, Choi S, Rinke ML, et al. Pediatric Type 1 Diabetes: Reducing Admission Rates for Diabetes Ketoacidosis. Qual Manag Health Care. 2016; 25(4): 231-237, doi: 10.1097/ QMH.0000000000000109, indexed in Pubmed: 27749721.

39. Cooper MN, de Klerk NH, Jones TW, et al. Clinical and demographic risk factors associated with mortality during early adulthood in a population-based cohort of childhood-onset type 1 diabetes. Diabet Med. 2014; 31(12): 1550-1558, doi: 10.1111/ dme.12522, indexed in Pubmed: 24925517.

40. Fazeli Farsani S, Brodovicz K, Soleymanlou N, et al. Incidence and prevalence of diabetic ketoacidosis (DKA) among adults with type 1 diabetes mellitus (T1D): a systematic literature review. BMJ Open. 2017; 7(7), doi: 10.1136/bmjopen-2017-016587, indexed in Pubmed: 28765134.

41. Ministerstwo Zdrowia. Mapy potrzeb zdrowotnych w zakresie cukrzycy dla wojewodztwa lubuskiego: 53-54. http://www.mpz.mz.gov. pl/wp-content/uploads/sites/4/2017/01/04_lubuskie.pdf (31.05.2017).

42. Wieckowska B. Healthcare needs maps - evidence informed healthcare policy. Journal of Health Policy \& Outcomes Research. 2017(1). 